\title{
Seismic retrofitting of non-engineered masonry in rural Nepal
}

Joshua Macabuag MEng

Structural Engineer, Building Design Partnership, National Society for Earthquake Technology, Nepal, India
Ramesh Guragain MEng

Director of Earthquake Engineering and Research Division, National Society for Earthquake Technology, Nepal

Subhamoy Bhattacharya PhD

Lecturer, Department of Civil Engineering, University of Bristol, UK

One of the greatest causes of casualties in major earthquakes around the world is the collapse of non-engineered masonry buildings (those built without engineering input). Yet by definition non-engineered structures remain largely outside of the scope of modern engineering research, meaning that the majority of those at risk often remain so. A further barrier to realising research in this field is the significant social and economic challenge of implementation in low-income communities, where non-engineered housing is prevalent. This paper introduces a retrofitting technique aimed at preventing or prolonging the collapse of adobe (mud brick) houses under strong earthquakes. This technique uses common polypropylene packaging straps to form a mesh, which is then used to encase structural walls. The aim of this paper is to give an overview of the retrofitting technique's development and implementation. The key development stages of static, dynamic and numerical testing are presented, showing that the proposed technique effectively prevents brittle masonry collapse and the loss of debris. An implementation project is then discussed, involving a training programme for rural masons in Nepal, a public shake-table demonstration and the retrofit of a real house. The implementation project proved effective at reaching rural communities but highlighted that government subsidies are required to incentivise the safeguarding of homes among low-income communities.

\section{Introduction}

\subsection{Motivation For this study}

'The replacement of existing dwellings with 'earthquake-resistant houses' is neither feasible nor, perhaps, desirable. It has been found more realistic to think, rather, in terms of low-cost upgrading of traditional structures, with the aim of limiting damage caused by normal earthquakes and giving their occupants a good chance of escape in the once-in-a-lifetime event of a large earthquake.' (Coburn and Spence, 2002).

Nearly $75 \%$ of all earthquake fatalities in the last century have resulted from building failures with a growing disparity between vulnerability of those in developing and developed countries (GeoHazards International, 2001). The greatest risk is by far presented to inhabitants of non-engineered masonry structures (Figure 1) as demonstrated in the 2003 Bam (Iran) earthquake, where many of the thousands of deaths were attributable to vulnerable adobe (mud brick) structures. Similarly vulnerable, non-engineered masonry is widespread throughout the developing world (Figure 2) and replacement of all such dwellings is both infeasible and undesirable, given that they are often the embodiment of local culture and tradition. Therefore, it is often more feasible to consider low-cost retrofitting of such buildings.

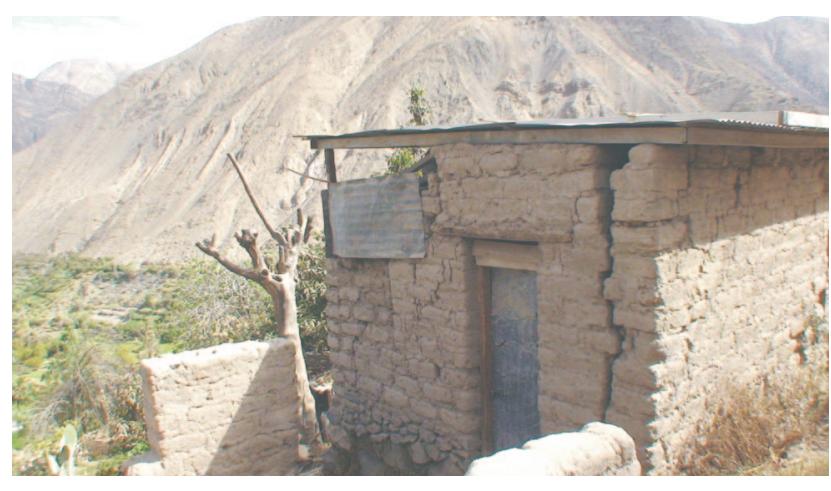

Figure 1. Non-engineered adobe house in Peru showing vertical crack and separation of orthogonal walls owing to out-of plane forces

It remains something of a paradox that the failures of non-engineered buildings that kill most people in earthquakes attract the least attention from the engineering profession.' (UN/ISDR, 2004).

Non-engineered adobe structures are classified by the European Macroseismic scale as being the most vulnerable category of housing (Grunthal, 1998). This is attributed to the nature of the material (high mass, low strength, brittle) and, in the case of low-cost housing, also the lack of proper design and 


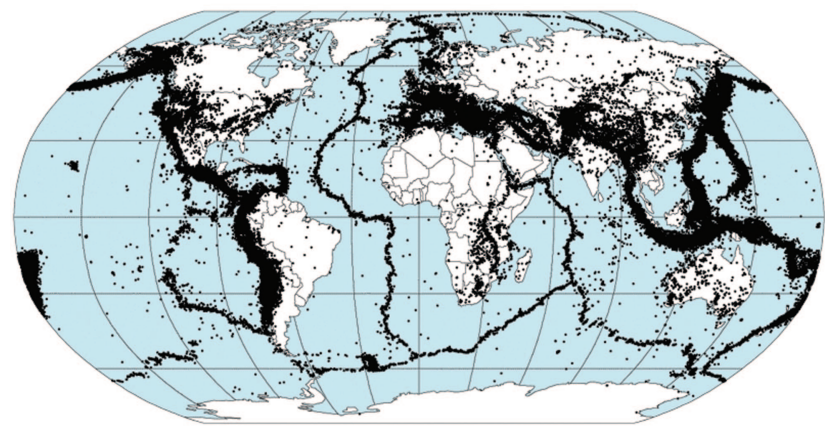

(a)

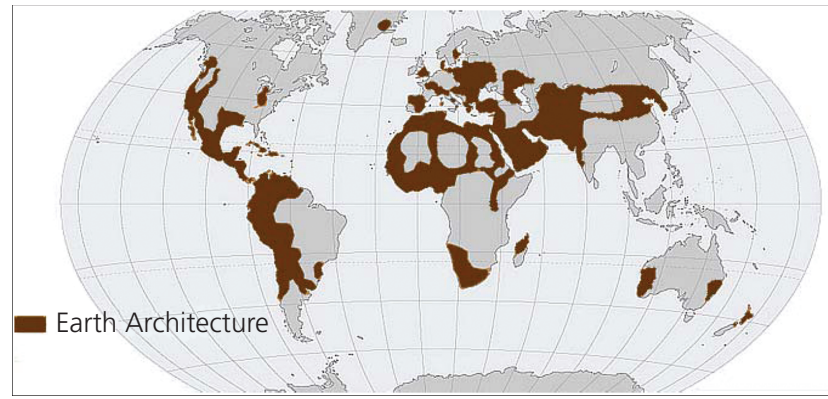

(b)

Figure 2. Geographical distribution of all recorded earthquake epicentres (left (Lowman and Montgomery, 1998)) and global distribution of adobe construction (right (De Sensi, 2003))

maintenance. Almost $50 \%$ of the population in the developing world live in earthen dwellings (Houben and Guillaud, 1994) (Figure 2) yet technical research into this housing type is limited. Consider, for example, the limited volume of design guidance and supporting research in the adobe building codes of, say, Peru and New Zealand, compared with established masonry design codes such as Eurocode 6 (BSI, 2005). Research is often not realised because of the difficulty of communicating developments to communities that conduct selfbuild without professional input. This paper, therefore, highlights some of the key stages of developing a seismic retrofit for non-engineered dwellings, from early development to community implementation.

\subsection{Currently available retrofitting techniques for non- engineered masonry}

Structural collapse under seismic loading displays many possible failure mechanisms often related to the interaction between structural components (e.g. separation of walls or floor-wall connections). When considering individual walls, earthquake loading can have components both within the plane of the wall (in-plane, Figure 5) and orthogonal to the plane of the wall (outof-plane, Figure 1).

Methods required to meet the needs of the large populations in danger of non-engineered masonry collapse must be simple and inexpensive to match the available resources and skills. Some examples of low-cost retrofitting techniques suitable for nonengineered, non-reinforced masonry dwellings are given in Table 1. There are several other examples in literature (Redman and Smith, 2009).

This paper focuses on the technique of polypropylene (PP) meshing and presents example numerical and physical tests that isolate the in-plane behaviour of masonry walls (sections 2.2 and 2.3).

\subsection{The applied element method for numerical modelling of block masonry}

Masonry is discontinuous, brittle and individual units (e.g. bricks) are free to separate, especially during dynamic loading. General finite element method (FEM) can simulate pre-failure behaviour in the linear-elastic range. Several FEM techniques and discrete element methods have been developed for non-linear modelling of effects such as crack propagation and structural collapse. However, these techniques are computationally intensive, limiting the size of models and duration of simulation. In the applied element method (AEM), the structure is discretised into elements, as in the FEM. However, the AEM elements are rigid, carry only the system's mass and damping and are connected at coincident faces with normal and shear springs representing the material properties

\begin{tabular}{lll}
\hline Method & Developing institute & Description \\
\hline Polypropylene (PP) meshing & $\begin{array}{ll}\text { Institute of Industrial Science (IIS), Tokyo } \\
\text { University, Japan. }\end{array}$ & $\begin{array}{l}\text { Encasing masonry walls with a mesh constructed of } \\
\text { polypropylene strapping used for packaging } \\
\text { worldwide (Mayorca and Meguro, 2001). }\end{array}$ \\
Wire meshing & Pontificia Universidad Católica del Peru, & $\begin{array}{l}\text { Similar to pp-meshing, but using a steel wire } \\
\text { (Macabuag, 2010). }\end{array}$ \\
External vertical bamboo & Seru. & External vertical bamboo reinforcement.
\end{tabular}

reinforcement

Table 1. Existing retrofitting techniques for non-reinforced

masonry in the developing world 


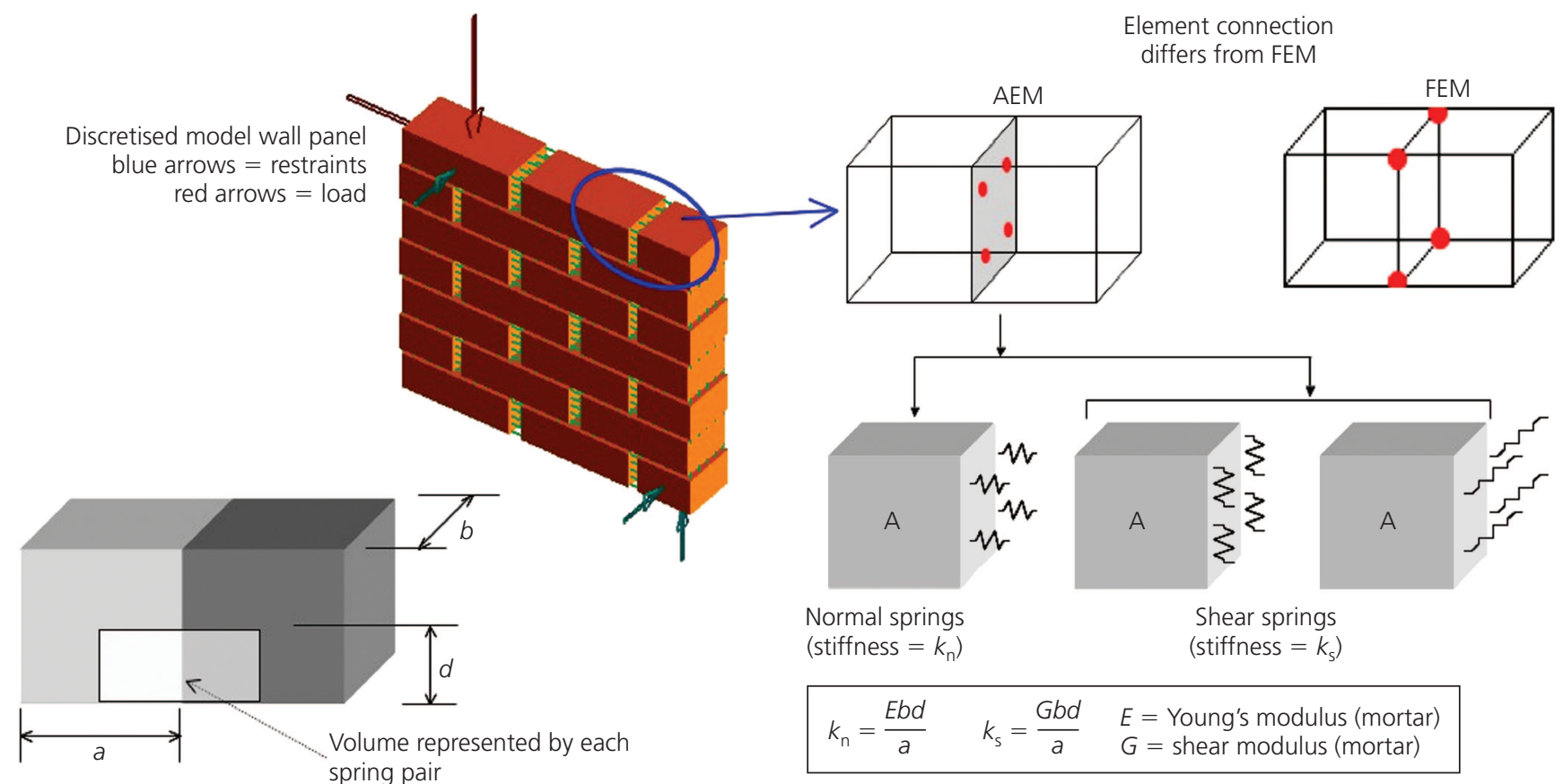

Figure 3. Applied element method (AEM) - element connectivity

(Figure 3). AEM can easily follow crack formation and propagation by allowing the separation of adjacent elements and is less computationally expensive than FEM for modelling similar effects (Meguro and Tagel-Din, 1997). AEM was originally developed by Meguro Lab, Tokyo University and is briefly introduced in this paper as a possible method for efficiently modelling masonry retrofitting techniques.

\subsection{Objectives}

This paper aims to give an overview of the development and implementation of a retrofitting technique for non-engineered adobe: PP meshing. The intended value of this overview is to highlight a major area of seismic risk and demonstrate the wider technical and socio-economical considerations of developing and delivering appropriate retrofitting techniques. The work presented is a mixture of literature review (where references are given) and work conducted by the authors.

Therefore, this paper will:

(a) present key stages in the development of PP meshing, giving examples of static, dynamic and numerical experimentation (section 2); detailed analysis will be omitted for brevity (the reader is directed to the references given), the objective being instead to provide an overview of the development process

(b) present a pilot project for the implementation of PP retrofitting in a seismically active region of Nepal (section 3); this is to highlight social and financial barriers to the dissemination of retrofitting techniques to low-income communities in developing countries.

\section{A proposed retrofitting technique: polypropylene meshing}

\subsection{Procedure and previous uses}

PP meshing uses common PP packaging straps (PP bands) to form a mesh, which is then used to encase masonry walls (i.e. fixing to both faces of each wall). The mesh prevents the separation of structural elements and the escape of debris, maintaining sufficient structural integrity to prevent collapse.

The mesh is formed by arranging the individual bands into a grid and electrically 'welding' at intersecting points (using a plastic welder such as that shown later in Figure 15(c)). Each wall to be retrofitted is stripped of existing render or covering, holes are drilled through the wall at regular spacing, anchor beams are installed at ground level (Figure 15(a), see later) and a ring beam at top of wall level if lacking. The mesh is connected to both faces of the wall, fixing to the anchor beams and ring beam and passing through openings and around corners with sufficient overlap. Meshes are connected together through the wall by wires passing through the previously drilled holes. Finally the mesh is rendered over protecting the mesh from sunlight, improving fixity to the wall and making the retrofit invisible (Figure 4).

PP bands are used as packaging the world over (e.g. tying furniture flat-packs in the UK) and are, therefore, cheap and readily available, while the retrofitting technique is simple and suitable for local builders. PP meshing has had application in Nepal, Pakistan and Kathmandu. Figure 4 shows a retrofitted house in Pakistan following the 2005 earthquake. 


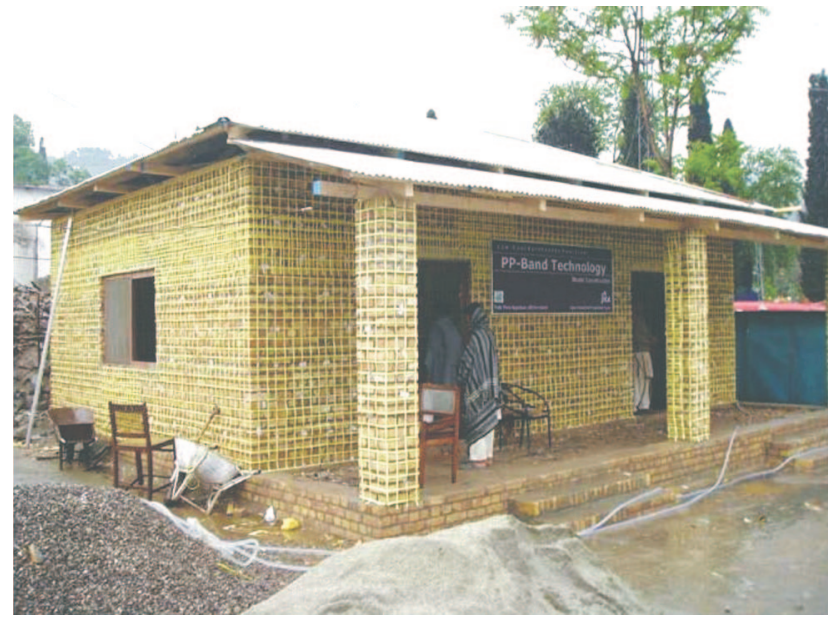

(a)

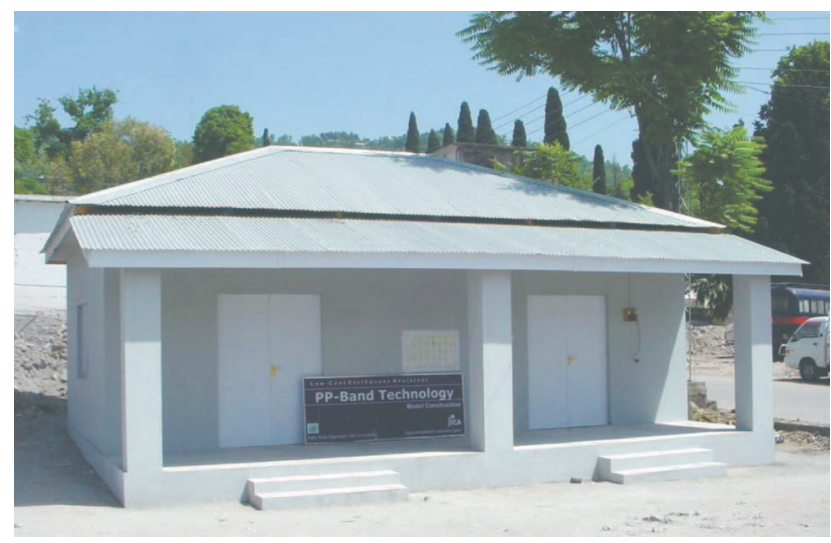

(b)

Figure 4. Retrofitted house in Pakistan before and after application of covering mortar layer. Note that the mesh is also applied to the inner face of the walls, with inner and outer meshes connected with through-wall ties. Photograph: Meguro Lab, Tokyo University

PP meshing was first formally proposed in 2000, and published in 2001 (Mayorca and Meguro, 2001). This section gives brief examples of some of the static, dynamic and numerical experimentation that has been carried out as well as a financial study into the impact of potential programmes for subsidising the retrofit to low-income communities. Practical details of the retrofitting method are discussed in Section 3.3.

\subsection{Static loading tests}

Correctly modelling individual failure mechanisms both demonstrates the action of the PP mesh and provides behavioural parameters for the development of an accurate earthquake model. This section presents tests isolating in-plane behaviour. Other isolated failure mechanisms can be found in literature (Meguro et al., 2005).

Determination of masonry shear resistance to in-plane lateral load was achieved by testing both retrofitted and non-retrofitted square prisms in compression along one diagonal (ASTM, 2002) (Figure 5). Full-size and small-scale modelling, at a linear scale of 1:4 was conducted. In addition to fully retrofitted masonry panels, meshes incorporating only vertical or horizontal bands were also tested to further isolate and understand the action of the mesh (Macabuag et al., 2008) (Figures 5(e) and 5(f)). PP bands were $12 \mathrm{~mm}$ wide and approximately $0.4 \mathrm{~mm}$ thick (exact measurement was not possible owing to a patterned surface). Rupture strength and failure strain of the bands used were measured in tension tests as $1.5 \mathrm{kN}$ and $14 \%$ respectively. Note that the normal procedure for forming the mesh is to electrically 'weld' bands at intersecting nodes (Figure 15(c), see later) but in this case each band was individually applied to the wall to differentiate from previous tests (Meguro et al., 2005) and investigate the effect of reduced mesh action by not fixing orthogonal bands to each other.

All failures of full and small-scale non-retrofitted walls were brittle with no further load being maintained, whereas retrofitted models continued to carry load after initial failure (Figure 6).

\subsubsection{Conclusions from static loading tests}

(a) Initial failure stress is unaffected by the presence of the mesh (Figure 6), as the stiffness of the masonry is far greater than that of the mesh and so the mesh is not engaged until the masonry deforms.

(b) Retrofitted specimens continued to maintain load after initial failure of the masonry.

(i) Retrofitting parallel to masonry rows directly resists the separation of bricks within the same row (Figure 5(e)).

(ii) Retrofitting perpendicular to masonry rows applies a force normal to the sliding brick courses, increasing their frictional resistance to further displacement (Figure 5(f)).

(c) The complete mesh effectively prevents loss of material and maintains wall integrity for large deformations, allowing redistribution of the load throughout the mesh and masonry. Note that the effectiveness of the mesh is less than that used in practice as this mesh was formed of individual bands not connected to one another, rather than the single coherent mesh recommended, yet a similar effect was achieved.

\subsection{Numerical modelling using the applied element method}

This section shows some simple in-plane shear models aimed at showing that the AEM can produce realistic behaviour for minimal computational requirements.

Figure 7 shows simulated diagonal compression tests giving realistic failure mechanisms using simple single-element bricks with connection springs containing the mortar properties, although this particular model required further refinement as failure loads were lower than those observed in physical tests. Figure 8 shows a more detailed study conducted by Meguro Lab, Tokyo University. The simulated test involved $9 \mathrm{kN}$ vertical 


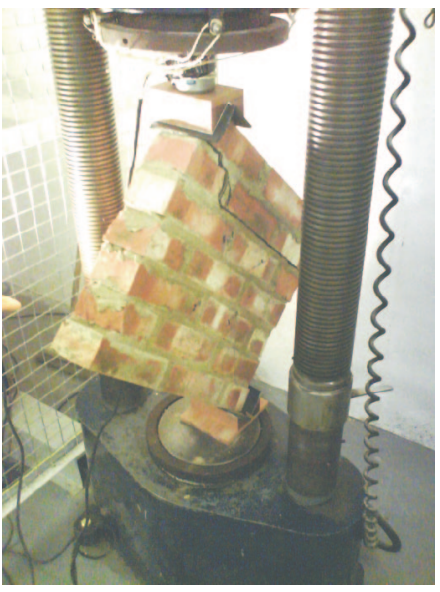

(a)

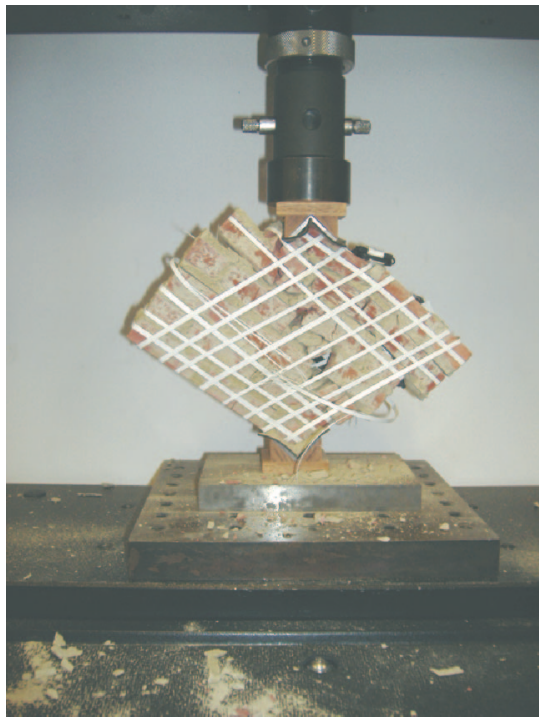

(d)

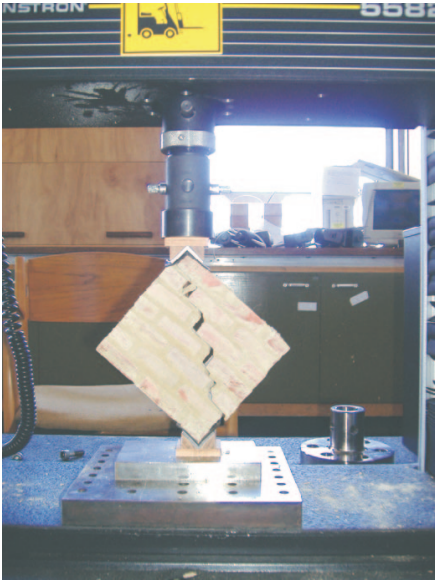

(b)

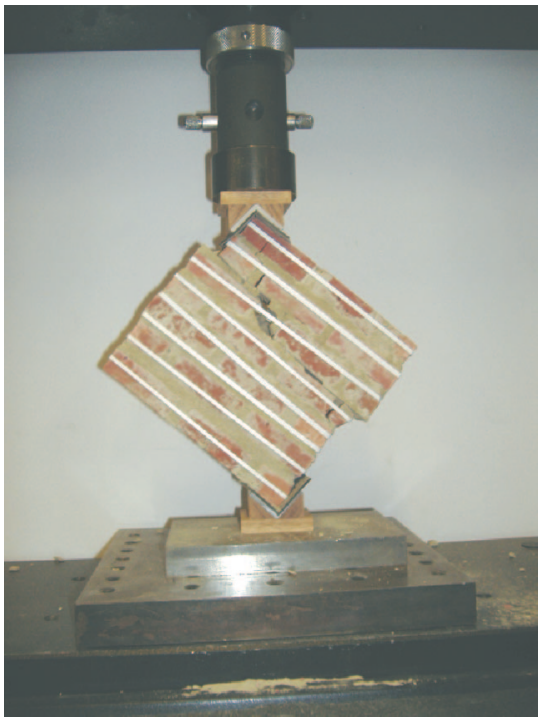

(e)

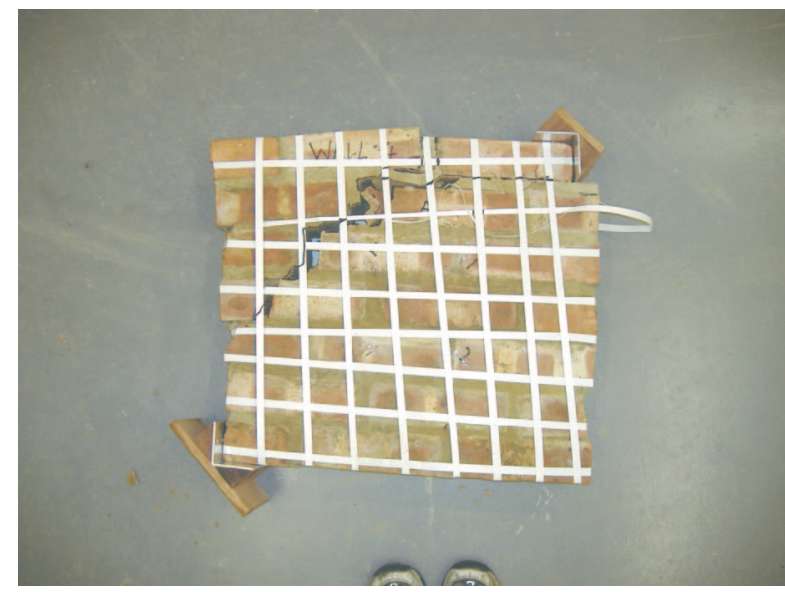

(c)

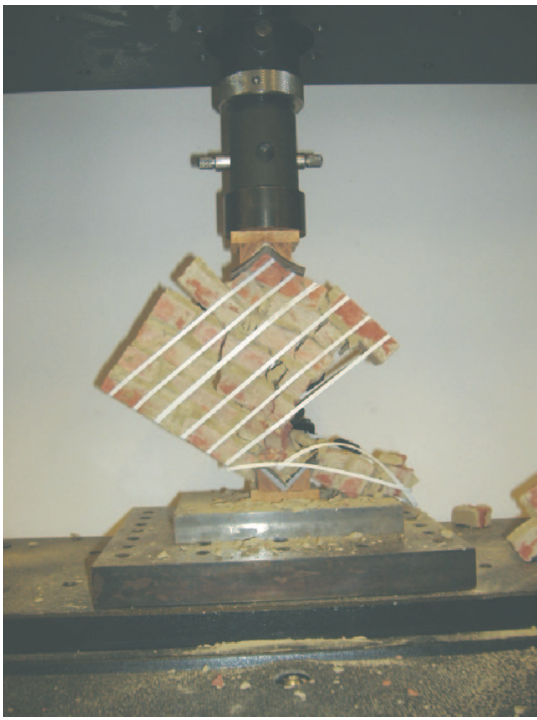

(f)

Figure 5. Full and small-scale model failures. (a) Full-scale specimen at brittle failure. (b) Small-scale specimen at brittle failure. (c) Full-scale specimen after testing. Note displacement and rotation of the corner section but maintained wall integrity. (d) Specimen continued to maintain load after second band failure. Further cracking suggests redistribution of load. (e) Intact sections suggest little redistribution of load. Total collapse observed after failure of the supporting band. (f) Load redistributing through specimen (shown by continued cracking) but little support offered by vertical bands. Note loss of debris

pre-loading of a masonry wall followed by displacement-controlled shearing (horizontal force applied to the top of the wall, within the plane of the wall). Behavioural patterns of flexural cracking and shear cracking were recreated, an accurate peak strength (just before shear cracking) was achieved and comparable post-peak behaviour was shown.

More complex models can be found in literature where AEM has been used for dynamic full-structure simulation through large deformation to progressive and ultimate collapse.

\subsubsection{Conclusions of numerical tests}

(a) AEM models of PP retrofitting produced realistic behaviour for minimal computational requirements.

(b) In comparison to many other numerical methods, AEM's 


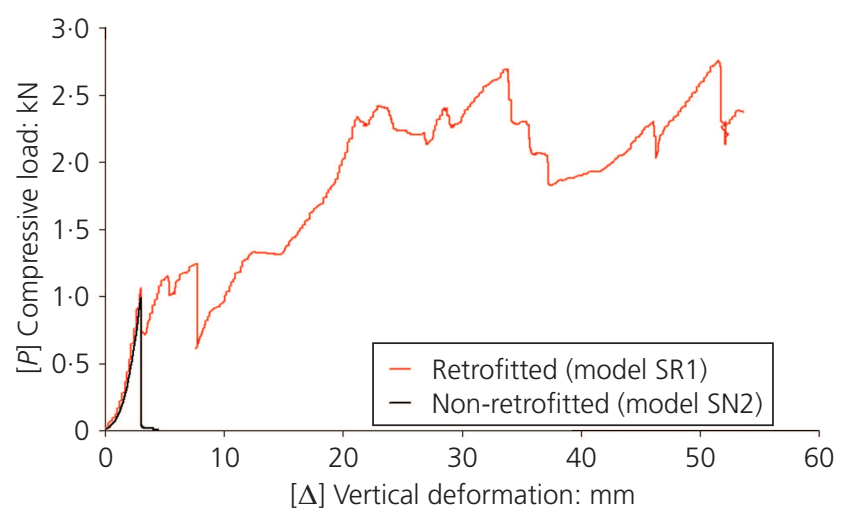

Figure 6. Load plotted against displacement for retrofitted and non-retrofitted small-scale models

ability to easily model element separation and interaction makes it suitable for the modelling of blocky masonry behaviour under static and dynamic loading, through cracking and large deformation to ultimate collapse.

\subsection{Dynamic testing, Tokyo University}

After developing a retrofit through static and numerical tests, it is necessary to consider the fully dynamic behaviour. The example below discusses full-scale shake-table testing conducted on retrofitted and non-retrofitted models by Meguro Lab, Tokyo University (Nesheli et al., 2006). Retrofitted models used fully coherent meshes, applied as described in section 2.1. Sinusoidal input motions, ranging from $2 \mathrm{~Hz}$ to $35 \mathrm{~Hz}$ with amplitudes from $0 \cdot 05 \mathrm{~g}$ to $1 \cdot 4 \mathrm{~g}$, were applied to obtain the dynamic response of the structures (Figure 9). Figure 10 shows their responses.

Shake table motion is given in terms of the Japan Meteorological Agency (JMA) seismic intensity scale, calculated from the shaketable peak acceleration for any given run. The JMA scale runs from 0 to 7 , with 7 being the strongest: for example, JMA 5+ corresponds to a peak ground acceleration of around $2.5 \mathrm{~m} / \mathrm{s}^{2}$, leading to the toppling of heavy furniture and severe difficulty for people to move.

\subsubsection{Conclusions from dynamic testing:}

(a) The result showed that the pp-band retrofit enhanced the seismic resistance of the masonry model significantly. Heavy structural damage capacity (D3) was enhanced from JMA 4 (for the non-retrofitted model) to JMA 6+ intensity (noting that this was also after several runs at lower intensities), and total collapse was prevented until JMA 7.

(b) By allowing cracking without the loss of wall integrity, the PP mesh enhances structural ductility and energy dissipation capacity whilst holding disintegrated structural elements together, thus preventing collapse.

(c) PP retrofitting was shown to enhance the safety of existing
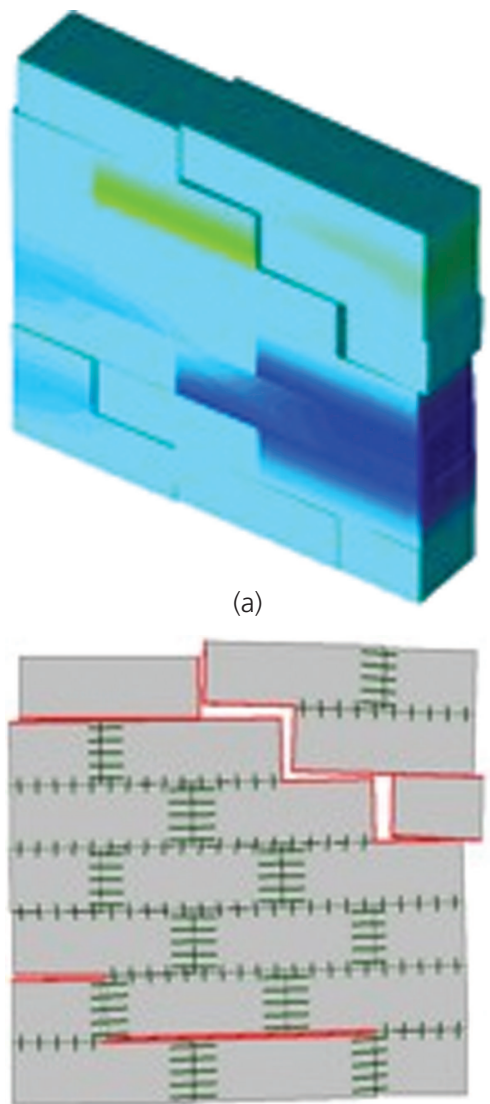

(b)

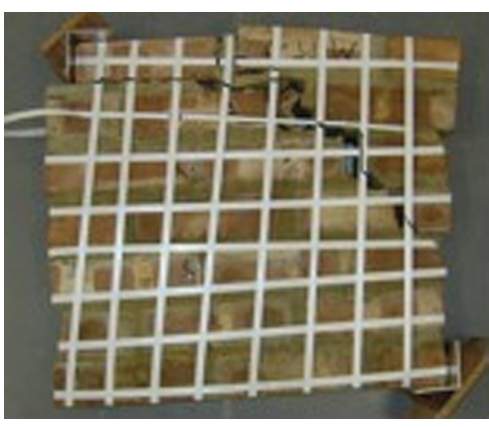

(c)

Figure 7. Simulated diagonal compression tests using the applied element method (AEM)

single-storey masonry buildings even in worst-case earthquake scenarios such as intensity JMA 7.

\subsection{Retrofit subsidisation programmes for low-income communities}

PP band retrofitting is specifically aimed at the lowest-income communities, costing about $\$ 30-\$ 70 /$ house for materials (Meguro, 2008). However, such lowest-income communities may struggle to meet basic needs and so retrofitting for earthquake safety still cannot be afforded without additional subsidy. 


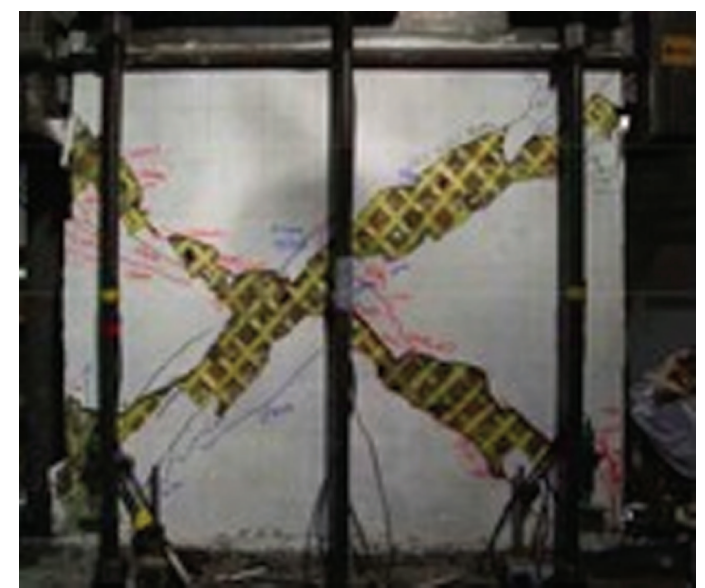

(a)

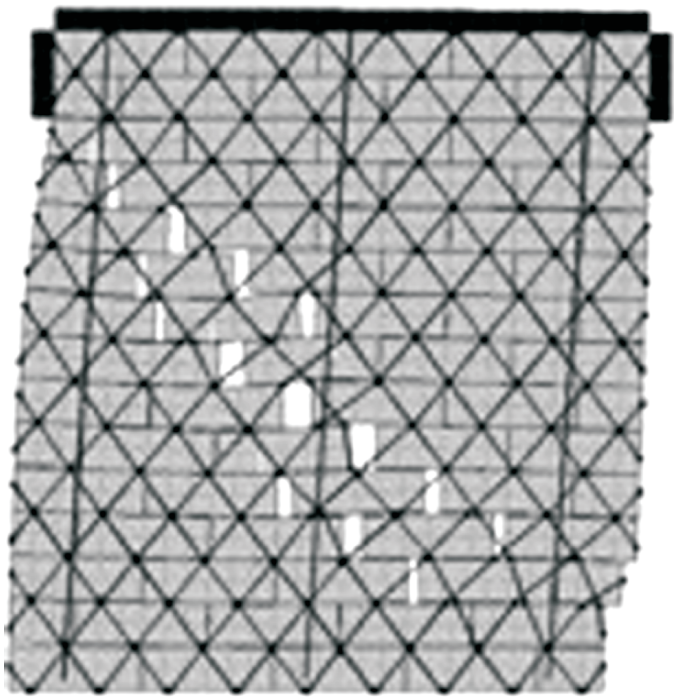

(b)

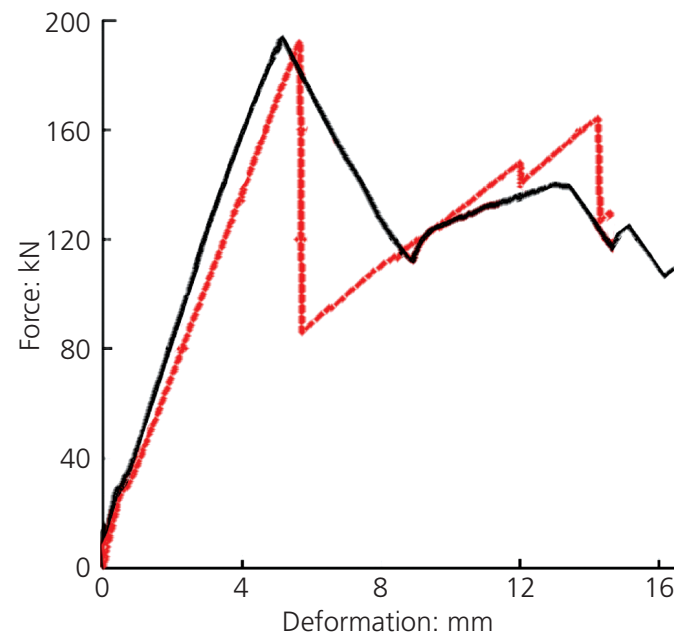

(c)

Figure 8. Comparison of real (black line) and simulated (grey line) shear test of a retrofitted wall using AEM (Mayorca and Meguro, 2001)]

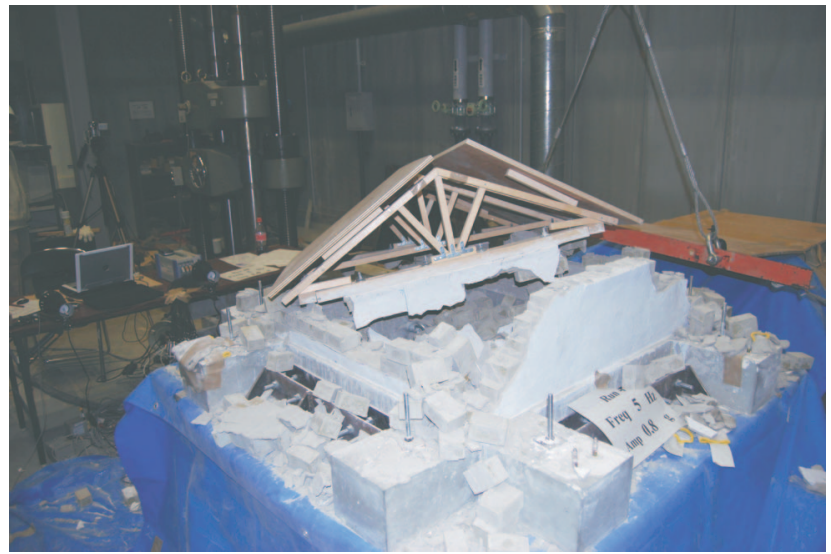

(a)

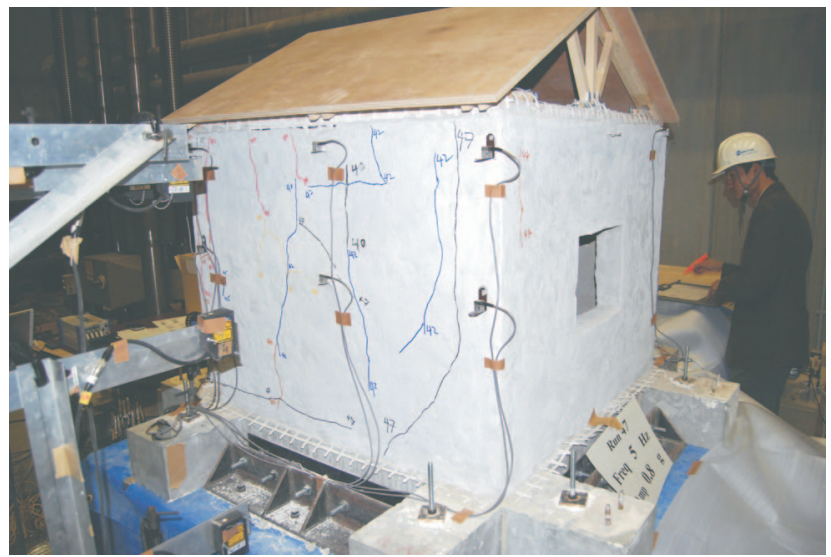

(b)

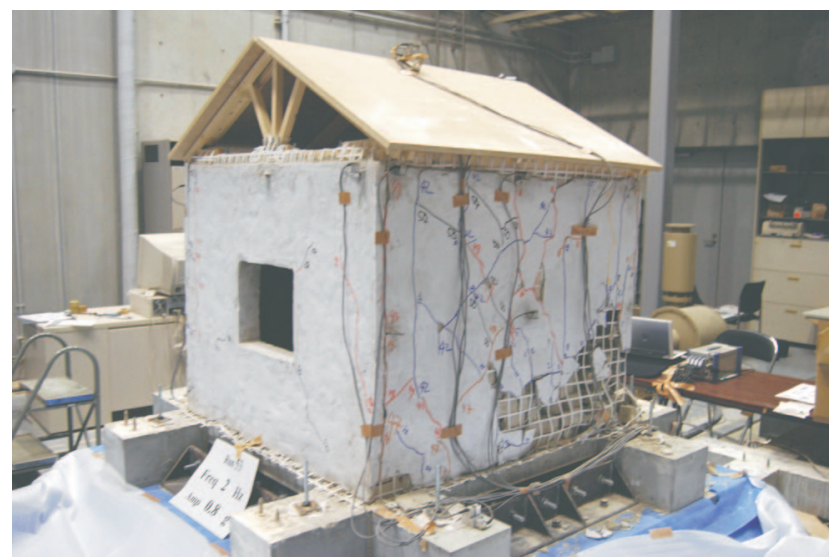

(c)

Figure 9. Full-scale shake table testing of non-retrofitted (a) and retrofitted (b, c) models (Nesheli et al., 2006): (a) Collapse of nonretrofitted model after 47 th run (intensity gradually increasing per run) at an earthquake intensity of JMA 5+. (b) Retrofitted model at JMA 5+ (the intensity at which the non-retrofitted model collapsed). Cracking has occurred but integrity is maintained. (c) Retrofitted model after 53rd run reaching JMA 6+ 


\begin{tabular}{|c|c|c|c|c|c|c|}
\hline Index & JMA 4 & JMA 5- & JMA 5+ & JMA 6- & JMA 6+ & JMA 7 \\
\hline
\end{tabular}

D0: No damage

D1: Light structural damage - Hair line cracks in very few walls.

The structure resistance capacity has not been reduce noticeably.

D2: Small cracks in masonry walls, falling of plaster block.

The structure resistance capacity is partially reduced.
D3: Heavy structural damage - Large and deep cracks in masonry walls Some bricks are fall down. Failure in connection between two walls.

D4: Partially collapse - Serious failure of walls. Partial structural failure of roofs. The building is in dangerous condition.

D5: Total or near collapse

\begin{tabular}{|c|c|c|c|c|c|c|c|c|}
\hline \multicolumn{9}{|c|}{ Table 2a: Performance of Non-Retrofitted Model } \\
\hline \multirow{2}{*}{$\begin{array}{l}\text { Acceleration } \\
\text { (g) }\end{array}$} & \multicolumn{8}{|c|}{ Frequency $(\mathrm{Hz})$} \\
\hline & 2 & 5 & 10 & 15 & 20 & 25 & 30 & 35 \\
\hline $1 \cdot 4$ & & & & & & & & \\
\hline $1 \cdot 2$ & & & & & & & & \\
\hline $1 \cdot 0$ & & & & & & & & \\
\hline 0.8 & & D5 & D3 & D3 & D2 & D2 & D1 & D1 \\
\hline $0 \cdot 6$ & & D5 & D3 & D2 & D2 & D2 & D1 & D1 \\
\hline $0 \cdot 4$ & & D4 & D3 & D2 & D2 & D1 & D1 & D1 \\
\hline $0 \cdot 2$ & D5 & DO & Do & Do & Do & Do & Do & D0 \\
\hline $0 \cdot 1$ & DO & DO & DO & D0 & DO & DO & D0 & D0 \\
\hline 0.05 & DO & DO & DO & DO & DO & DO & DO & DO \\
\hline
\end{tabular}

\begin{tabular}{|c|c|c|c|c|c|c|c|c|}
\hline \multicolumn{7}{|c|}{ Table 2b: Performance of Retrofitted Model } \\
\hline $\begin{array}{c}\text { Acceleration } \\
(\mathrm{g})\end{array}$ & \multicolumn{7}{|c|}{ Frequency (Hz) } & \multicolumn{2}{c|}{35} \\
\hline & 2 & 5 & 10 & 15 & 20 & 25 & 30 & \\
\hline 1.4 & & D3 & & & & & & \\
\hline 1.2 & D4 & D3 & & & & & & \\
\hline 1.0 & & D2 & & & & & & D0 \\
\hline 0.8 & D4 & D2 & D2 & D2 & D1 & D1 & D0 & D0 \\
\hline 0.6 & D3 & D2 & D2 & D1 & D1 & D0 & D0 & D0 \\
\hline 0.4 & D3 & D2 & D2 & D1 & D1 & D0 & D0 & D \\
\hline 0.2 & D2 & D0 & D0 & D0 & D0 & D0 & D0 & D0 \\
\hline 0.1 & D0 & D0 & D0 & D0 & D0 & D0 & D0 & D0 \\
\hline 0.05 & D0 & D0 & D0 & D0 & D0 & D0 & D0 & D0 \\
\hline
\end{tabular}

Figure 10. Performance and damage levels of full-scale models under dynamic loading: (a) performance on non-retrofitted model; (b) performance of retrofitted model (Meguro, 2008) 
Considering this economical issue is, therefore, crucial to be able to disseminate the technology to the low-income communities that most need it.

Meguro Lab, Tokyo University has proposed several systems for subsidising seismic retrofits including the 'two-step incentive system' (Meguro, 2008) and 'new earthquake micro-insurance system'. In the proposed two-step incentive system, house owners are encouraged to retrofit their homes by receiving the necessary materials and a subsidy upon satisfactorily carrying out the work. If the retrofitted houses are damaged in an earthquake, the owners then receive twice the compensation than the house owners who did not retrofit (Figure 11). Table 2 shows predictions for the number of lives saved for several earthquakes, using data from dynamic experiments (such as that presented in section 2.4) to calculate the percentage of building collapses that could have been prevented.

Considering the percentage of buildings potentially saved (Table 2) the reduction in expenditure of both the government and

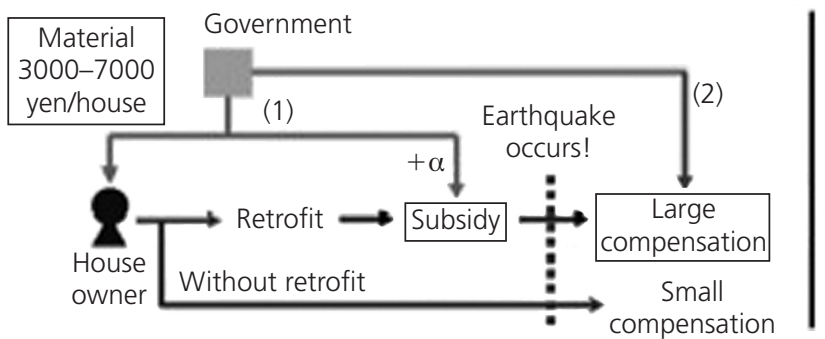

Figure 11. Subsidisation programme - 'two-step incentive system' (Meguro, 2008). Note $1 \mathrm{GBP}=200$ yen (approximately) homeowners if this two-step incentive system had been in place was also estimated (Figure 12).

\section{Implementation of the proposed retrofitting technique}

To investigate the practical issues of implementation a pilot scheme was conducted in a seismically active region of the Kathmandu Valley, Nepal.

The Himalayan region is an example of one area of constant seismic activity, high population density, and wide-spread use of non-reinforced masonry built outside of current building standards. Given the high potential for future loss of life several PP band implementation programmes have been run in this region.

Given that the dwellings most at risk are built outside of building regulations it is clear that a sustainable solution can only be achieved by raising local awareness of available methods and allowing the building owners and tradesman to themselves become the disseminators of the proposed solution.

In 2006 a public, low-tech shake-table demonstration was held in Kashmir (following the 2005 earthquake) followed by the retrofit of a full-scale building by local masons under supervision (Figure 4). Material costs for the retrofit were around US\$30 and the total installation cost was less than $5 \%$ of the total construction cost.

This section describes an implementation programme conducted in November 2008, funded by the Mondialogo Engineering Award. The programme was conducted as a partnership between Oxford University; the Institute of Industrial Science, Tokyo University; the Indian Institute of Technology, Bombay; Nepal Engineering College; Khwopa Engineering College, Nepal and the National Society of Earthquake Technology (NSET). The implementation project involved a six-day training course for

\begin{tabular}{|c|c|c|c|c|c|c|}
\hline & \multicolumn{2}{|c|}{ Bam earthquake (2003) } & \multicolumn{2}{|c|}{ Kashmir earthquake (2005) } & \multicolumn{2}{|c|}{ Java earthquake (2006) } \\
\hline & $\begin{array}{l}\text { Without } \\
\text { retrofitting }\end{array}$ & $\begin{array}{l}\text { Estimated with } \\
\text { retrofitting }\end{array}$ & $\begin{array}{l}\text { Without } \\
\text { retrofitting }\end{array}$ & $\begin{array}{l}\text { Estimated with } \\
\text { retrofitting }\end{array}$ & $\begin{array}{l}\text { Without } \\
\text { retrofitting }\end{array}$ & $\begin{array}{l}\text { Estimated with } \\
\text { retrofitting }\end{array}$ \\
\hline Totally collapsed houses & 49000 & $\begin{array}{c}8200 \\
\text { (83\% reduction) }\end{array}$ & 203579 & $\begin{array}{c}5847 \\
\text { (97\% reduction) }\end{array}$ & 154098 & $\begin{array}{c}13080 \\
\text { (92\% reduction) }\end{array}$ \\
\hline Partially collapsed houses & & & 196573 & $\begin{array}{c}67561 \\
\text { (66\% reduction) }\end{array}$ & 199,160 & $\begin{array}{c}78550 \\
\text { (61\% reduction) }\end{array}$ \\
\hline $\begin{array}{l}\text { Fatalities due to total } \\
\text { collapses }\end{array}$ & 43200 & $\begin{array}{c}7275 \\
\text { (83\% reduction) }\end{array}$ & 58668 & $\begin{array}{c}1685 \\
\text { (97\% reduction) }\end{array}$ & 4559 & $\begin{array}{c}387 \\
\text { (92\% reduction) }\end{array}$ \\
\hline $\begin{array}{l}\text { Fatalities owing to partial } \\
\text { collapses }\end{array}$ & & & 16367 & $\begin{array}{c}5625 \\
\text { (66\% reduction) }\end{array}$ & 1140 & $\begin{array}{c}450 \\
\text { (61\% reduction) }\end{array}$ \\
\hline
\end{tabular}

Table 2. Reduction in casualties had the 'two-step incentive system' been adopted (Meguro, 2008) 


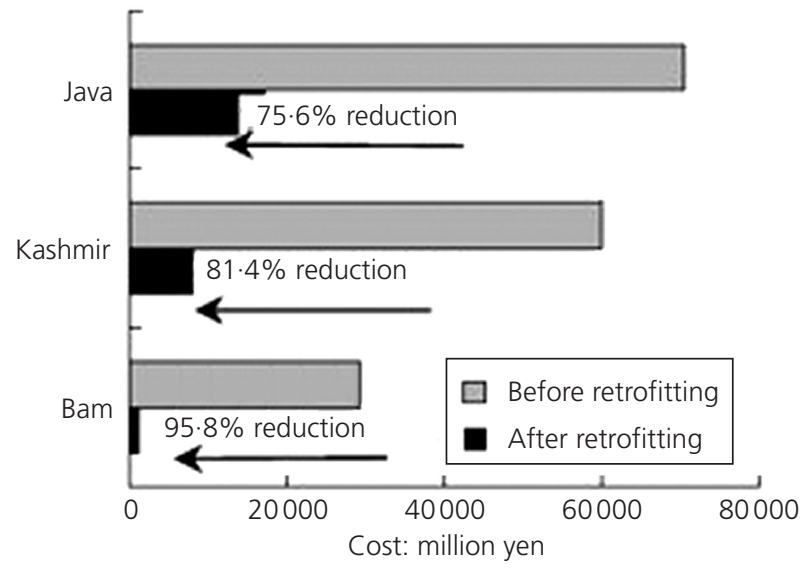

(a)

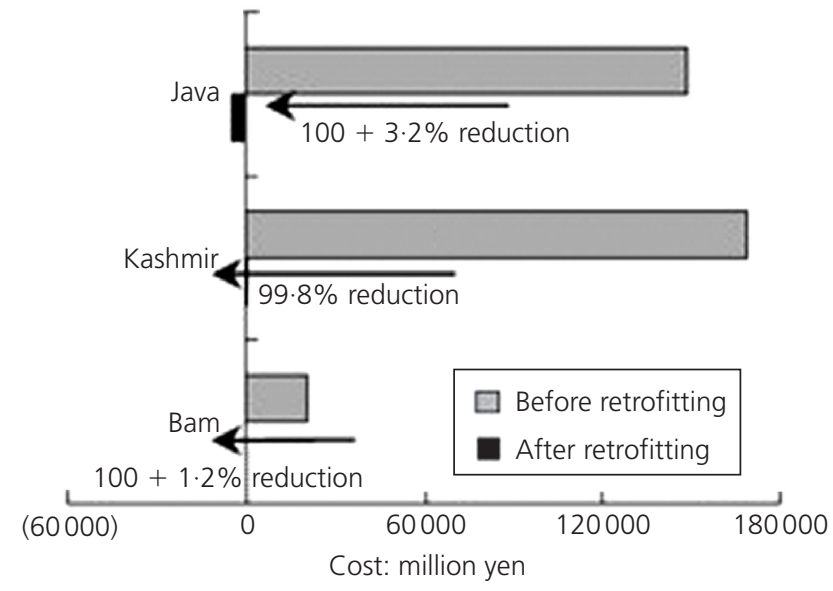

(b)

Figure 12. Reduction in expenditure had the 'two-step incentive system' been adopted (Meguro, 2008). Note 1 pound $=200$ yen (approximately)

local, rural masons, focusing on both earthquake construction and the pp-retrofitting technique. At the end of the course was a public low-tech shake-table demonstration of the PP band technology, inviting the community, press and key individuals and institutions.

\subsection{Training programme for rural masons}

The training course was coordinated by Khwopa Engineering College and engaged rural masons in several aspects of earthquake construction: appropriate site selection, building layout and construction techniques (in masonry, timber and reinforced concrete (RC)), strengthening and repairing of existing structures and retrofitting using the PP mesh.

Many of the masons were very experienced in their trades but had never received training, or a formal education (a high level of illiteracy is another reason why a training course is required over simply producing training manuals). The aim was, therefore, to introduce small changes to current practice that can be implemented through simple rules of thumb but which significantly improve building earthquake safety. Some example features are shown in Figure 13.

Figure 13(a) shows a load bearing masonry wall with buttressing and vertical reinforcement and with the masons preparing to add horizontal reinforcement at corners and orthogonal walls. Figure 13(b) shows often-omitted details for local RC frames such as a double-cage for the column with a link within the beam/column joint and the beam rebar being completely contained within the column rebar and continuous through the joint.

Figure 13(c) shows a simplified introduction to applying the PP mesh to a masonry wall. Note that the PP mesh would not usually be applied in conjunction with internal reinforcement but was applied to the reinforced masonry model (Figure 13(a)) purely as a simple tool for demonstrating the basics of applying the mesh. During the course it was stressed that PP retrofitting is intended for use with adobe where holes can be drilled through bricks as well as mortar, allowing more accurate spacing of through-wall connectors, giving a tighter mesh. The real retrofit is also continued and overlapped around corners and through openings and connected to the foundations and ring-beam (Figure 15, see below)

\subsection{Public low-tech shake table demonstration}

The public demonstration was coordinated by NSET, involved two 1:6 scale masonry models (one with the PP mesh and one without) and utilised a simple spring-loaded shake-table (Figure 14). The demonstration was designed to allow the masons to apply what they had learnt, for the public to graphically witness the necessity to safeguard their homes and to encourage municipalities and other potential funders to adopt a retrofitting programme. The event received radio and television coverage in Nepal. Note that the simple table used is not intended to simulate accurate earthquake motion, but simply to demonstrate the effect that general ground motion can have on structures.

\subsubsection{Outcomes of training course and demonstration}

Following the training course, feedback from the masons was that they were motivated on the need for earthquake safety, very positive to be armed with simple rules-of-thumb that can be implemented easily but have an impact and keen to learn more about the PP retrofit.

The main feedback from the community after the demonstration was that community members were also motivated on the need for earthquake safety, keen to retrofit their homes but concerned over the cost of retrofitting. Municipalities and officials were keen to retrofit homes but concerned over costs.

This shows that once awareness has been raised, people are keen to safeguard their homes but subsidisation will be necessary if retrofitting is to be an option for low-income communities. It can also be seen that studies, such as that given in section 2.5 , are 


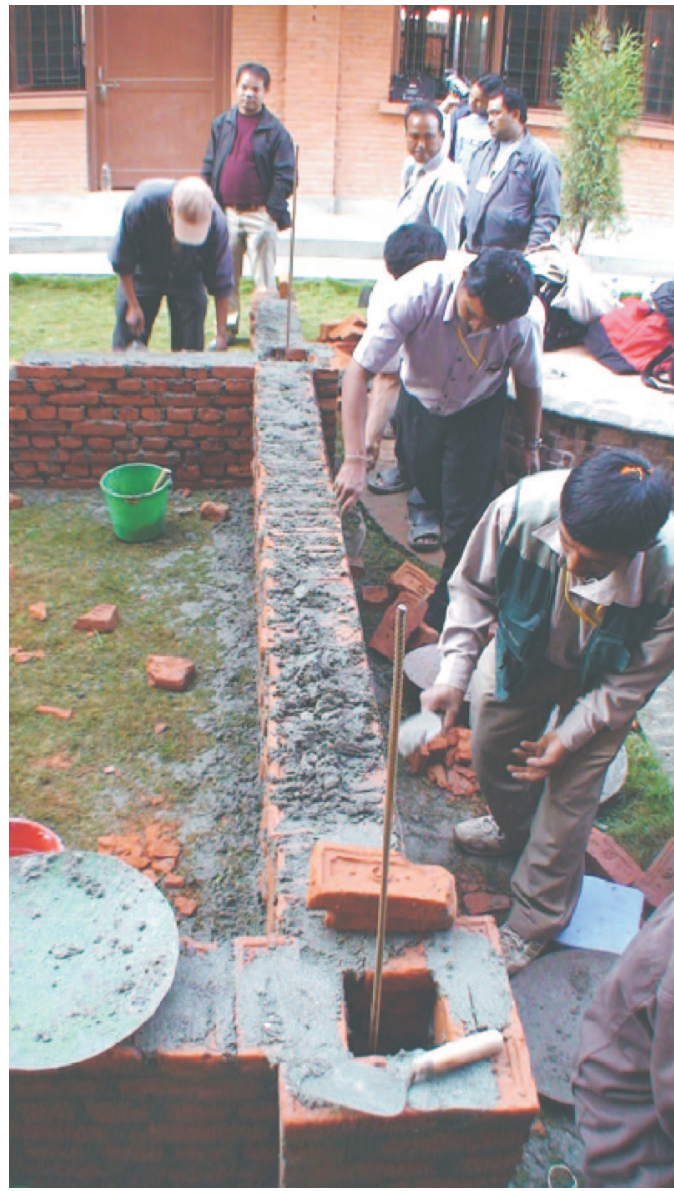

(a)

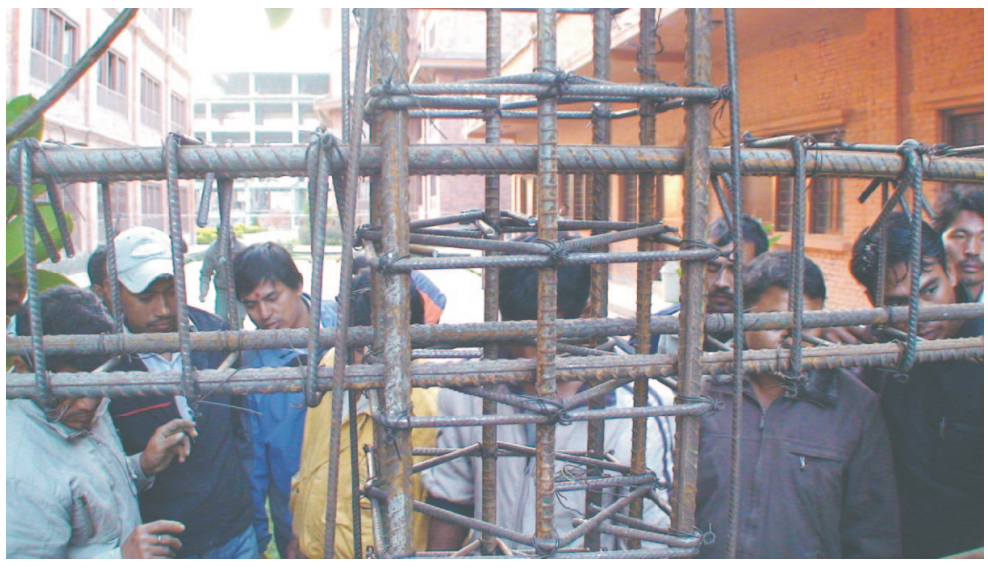

(b)

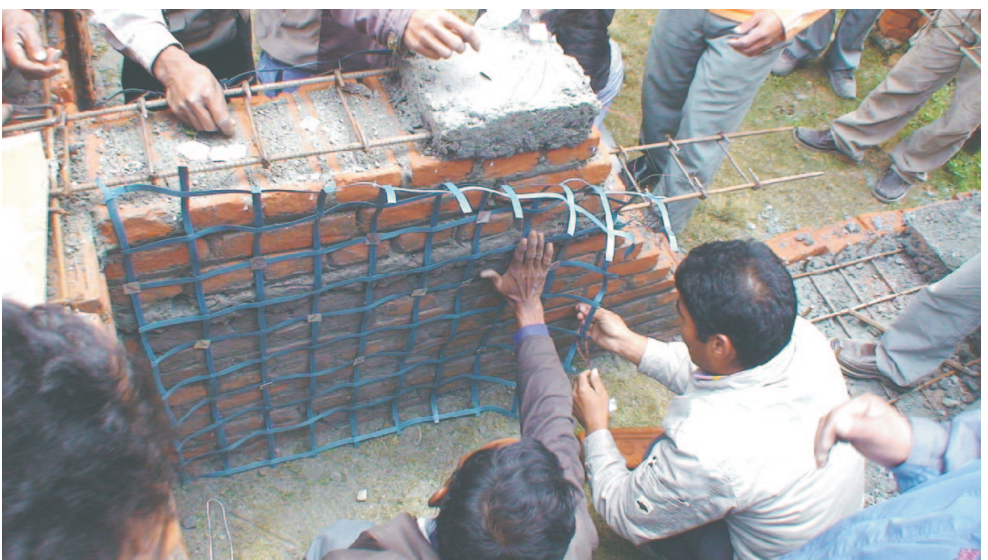

(c)

Figure 13. Six-day training programme for rural masons, Bhaktapur, Nepal 2008

necessary to quantitatively show municipalities and other funders the benefits of pre-emptively retrofitting rather than rebuilding post-disaster.

\subsection{Real retrofit of adobe home in Nepal}

The final stage of the pilot implementation programme involved retrofitting an adobe residential building in Nangkhel Village of Bhaktapur District, Nepal. The masons involved had taken part in the training course from section 3.1. The objectives of the real scale implementation work were:

(a) to retrofit a pilot building using the PP band retrofitting technique

(b) to observe practically the technical, economical and cultural appropriateness of the retrofitting technique under the local site conditions

(c) to give hands-on training to the local masons on the retrofitting technique and receive feedback and practical suggestions to improve the retrofitting process.
The retrofitting procedure differed from that used previously (section 2.1) in that rather than preparing the mesh off-site and fixing to the wall, the mesh was formed directly onto the wall (Figures 15(b) and (c)). This change was proposed by the masons themselves to improve buildability and it was suggested that in this way, it might no longer be necessary to connect the bands using the plastic welder for future projects (previously the most expensive part of the retrofit technique). This suggestion requires further investigation (e.g. following on from work in section 2.2).

The general process of the retrofit can be seen in Figure 15. An anchor beam was first fixed to the base of the wall inside and out; vertical PP bands were fixed between the internal and external base anchor beams; horizontal bands were then woven between and welded to the vertical bands; meshes on opposite faces of each wall were connected to each other through the wall by steel wires passing through drilled holes; finally a render was applied to cover the mesh. Note that this house also required additional refurbishment work in replacing rotten floor and roof beams and infilling unnecessary openings. 


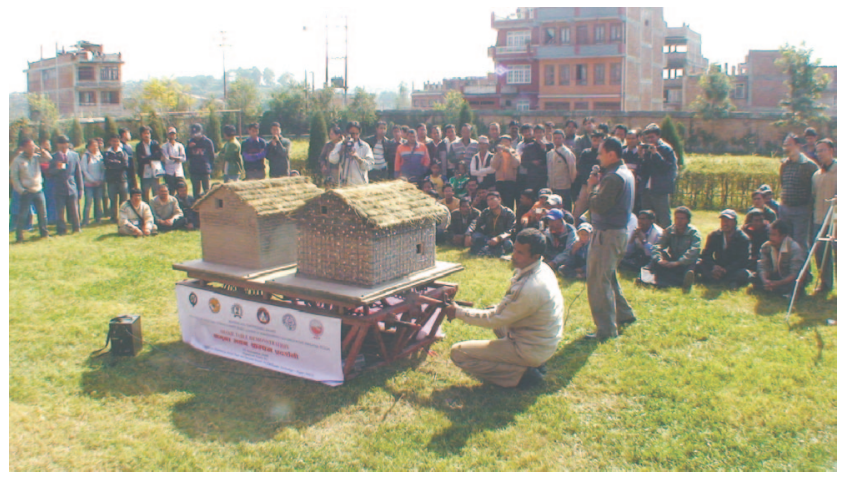

(a)

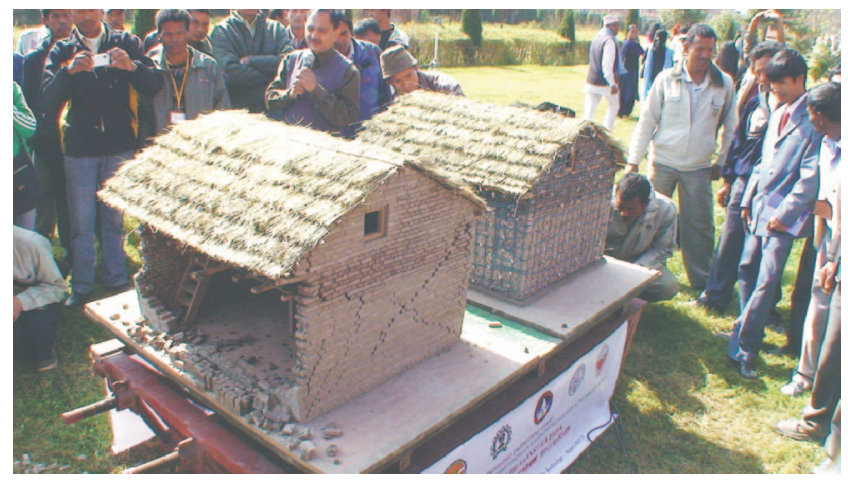

(c)

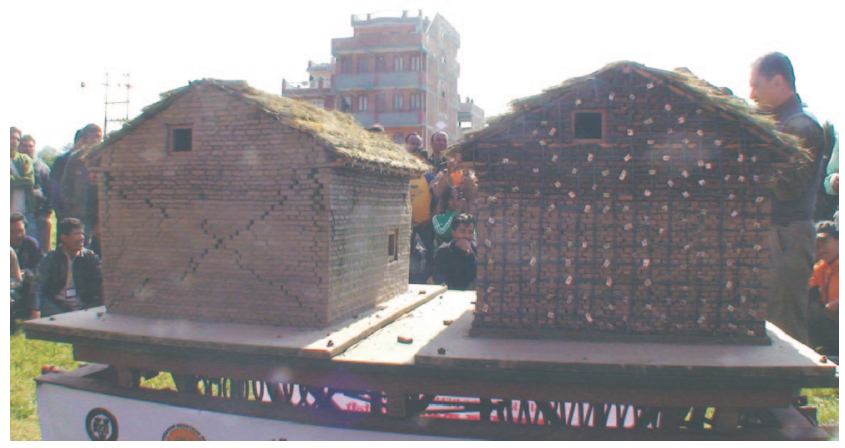

(b)

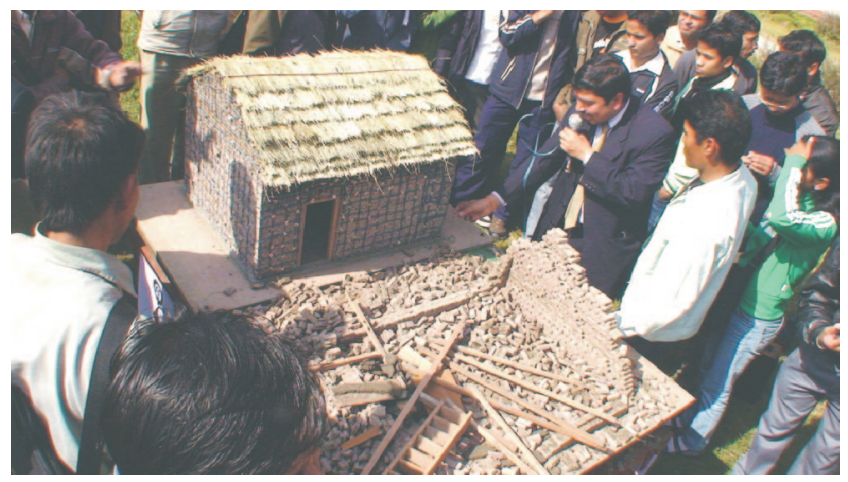

(d)

Figure 14. Public demonstration, Bhaktapur, Nepal 2008

The work was carried out by one NSET technician, two masons and two unskilled labourers over 4 weeks. The material costs associated with the PP retrofit came to \$250. Details on full-scale retrofitting and the process described here are given in the final report of the implementation work (NSET, 2009).

The outcomes of the live retrofit were as follows:

(a) the retrofit was successfully implemented and showed that it is technically feasible to retrofit residential adobe houses using the PP band retrofitting technique

(b) by training through hands-on implementation the masons are now able to do this type of retrofitting independently

(c) the modification to the retrofitting process proposed by the masons of forming the mesh directly onto the wall proved an effective time saver; this highlights the potential benefits of developing the technique alongside those who will implement it.

\section{Summary and recommendations}

This paper has introduced the technique of polypropylene meshing for preventing or prolonging the collapse of adobe buildings under strong earthquakes. Both development and implementation of this technique was considered. The main findings during the development of PP meshing are as follows: (a) the complete PP mesh prevents loss of material and maintains wall integrity for large deformations, allowing redistribution of the load throughout the mesh and masonry

(b) PP retrofitting was shown to enhance the safety of existing single-storey masonry buildings even in worst-case earthquake scenarios such as intensity JMA 7

(c) PP band technology is cheap, readily available and easy to install, so is suitable as a retrofit for low-income communities

(d) In comparison to many other numerical methods, the ability of the AEM to easily model element separation and interaction makes it suitable for modelling the behaviour of blocky masonry plus retrofit through cracking and large deformation to ultimate collapse. AEM is, therefore, a suitable tool when developing retrofitting methods for the large number of masonry types available.

The main objective of the implementation work was to help disseminate safer seismic construction and retrofitting techniques to rural communities with a high proportion of non-engineered dwellings.

(a) The pilot implementation programme in Kathmandu, Nepal (training course for rural masons and public shake-table demonstration) showed that

(i) directly engaging masons is an effective way of 


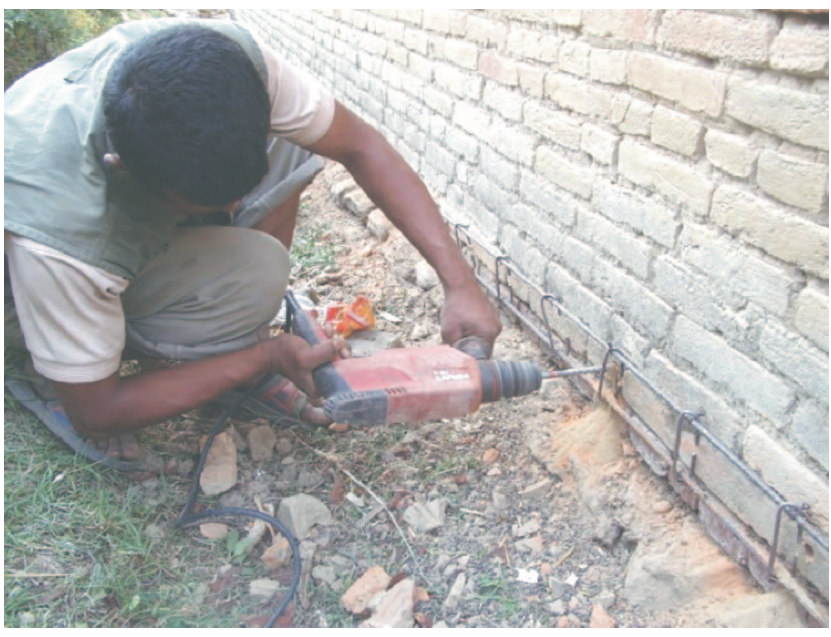

(a)

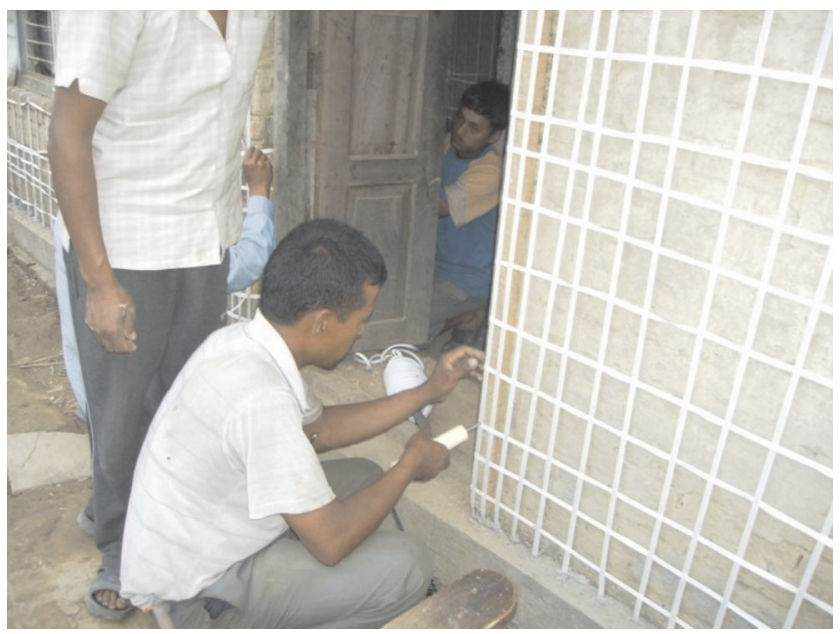

(c)

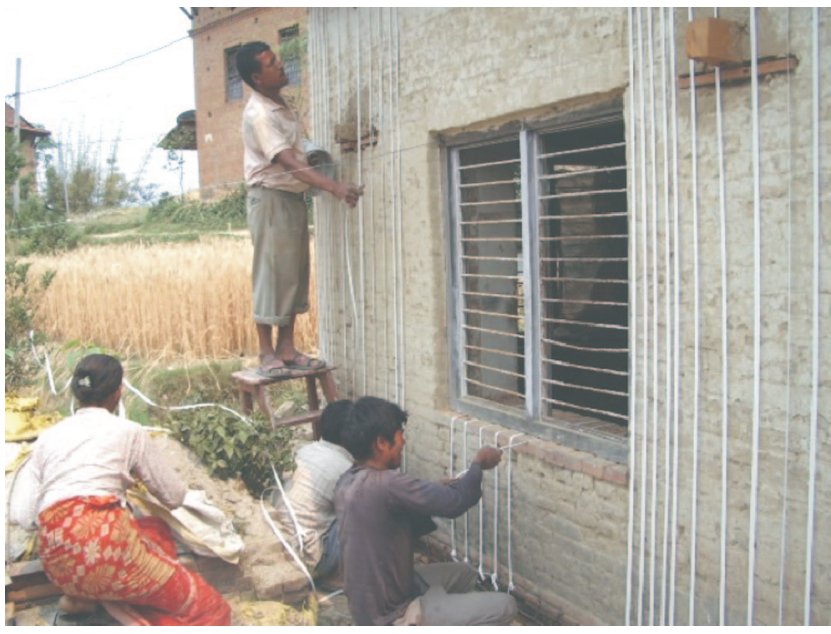

(b)

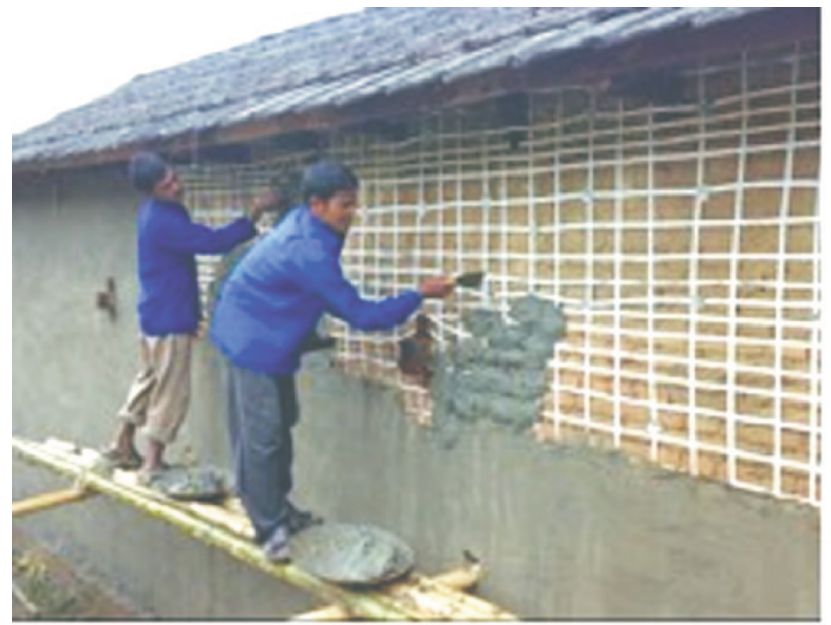

(d)

Figure 15. Retrofit of a real adobe dwelling, Nangkhel, Nepal 2009. Photographs: NSET

transferring knowledge of earthquake-safe construction directly to those responsible for the construction

(ii) communities and officials are keen to retrofit homes but despite the low-cost, were still concerned over expense for low-income communities where supply of basic needs was more urgent.

(b) Subsidisation schemes are required to make retrofitting an attractive option for low-income households. The increased number of retrofits would in-turn lead to a substantial reduction in loss of life and cost following the next strong earthquake, for both governments and homeowners.

\section{Acknowledgements}

Thanks also go to the Mondialogo Engineering Award organizers, UNESCO, and the award team: National Society for Earthquake Technology, Nepal (NSET) for their support and role as implementers for the fieldwork in Nepal; Meguro Lab, Industrial
Institute of Science, Tokyo University for their pioneering work in this field and invaluable support and encouragement; Louisa Man and Peter Brice for their hard work in bringing our implementation ideas to fruition; and Khwopa Engineering College, Nepal for their support and role as implementers for the training and demonstration programmes in Nepal.

\section{REFERENCES}

ASTM (2002) E 519-02: Standard test method for diagonal tension (shear) in masonry assemblages. ASTM, Philadelphia, USA.

BSI (2005) Eurocode 6: BS EN 1996: design of masonry structures. BSI, London, UK.

Coburn A and Spence R (2002) Earthquake Protection, 2nd edn. John Wiley, New York, USA.

De Sensi B (2003) Soil, the dissemination of earth architecture. See www.terracruda.com/architetturadiffusione.htm. 
GeoHazards International (2001) Global Earthquake Safety Initiative - Pilot Project. United Nations Centre for Regional Development, Bogota.

Grunthal G (1998) European Macroseismic Scale. European Seismological Commission, Ljubljana.

Houben H and Guillaud H (1994) Earth Construction - A Comprehensive Guide. ITDG Publishing, London, UK.

Lowman P and Montgomery B (1998) Preliminary determination of epicentres (of) 358,214 events (between) 1963 and 1998. NASA image obtained from http://denali.gsfc.nasa.gov/dtam/ seismic/.

Macabuag J, Bhattacharya S and Blakeborough A (2008) Extending the collapse time of non-engineered masonry buildings under seismic loading. Proceedings of the 14th World Conference on Earthquake Engineering, Beijing, pp. 4-7.

Macabuag J (2010) Seismic reinforcement of adobe in rural Peru. The Structural Engineer 88(23/24).

Mayorca P and Meguro K (2001) Strengthening of masonry structures - an ongoing research. In Japan-Peru Joint Workshop on the Earthquake and Tsunami Disaster Mitigation Technologies and Their Integration for the AsiaPacific Region, Lima (Konagai, K and Zavala C (eds)).

Meguro K (2008) Technological and social approaches to achieve earthquake safer non-engineered houses. Proceedings of The 14 World Conference on Earthquake Engineering, Beijing pp. 3-5.

Meguro K, Sathiparan N, Mayorca P, Guragain R and Nesheli N
(2005) In-plane and out-of-plane behaviour of PP-Band retrofitted masonry wallettes. In 10th International Symposium on New Technologies for Urban Safety of Mega Cities in Asia, 12-14 October 2011, Chiang Mai, Thailand. United Nations University Institute for Sustainability and Peace, Tokyo.

Meguro K and Tagel-Din H (1997) An efficient technique for fracture analysis of structures. Bulletin of Earthquake Resistant Structure Research Centre 30: 103-116.

NSET (National Society for Earthquake Technology) (2009) Final Report on Retrofitting of a Full Scale Adobe Building by PPband Retrofitting Technique. NSET, Nepal, India.

Nesheli K, Sathiparan N, Guragain R et al. (2006) Full-scale shaking table tests on masonry buildings retrofitted by PPband meshes. Proceedings of the 5th International Symposium on New Technologies for Urban Safety of Megacities in Asia, Phuket. United Nations University Institute for Sustainability and Peace, Tokyo.

Redman T and Smith A (2009) A critical review of retrofitting methods for unreinforced masonry structures. Proceedings of the Engineers Without Borders - UK National Research Conference 2009: The Social Dimensions of Engineering Research, London.

UN/ISDR (Inter-Agency Secretariat of the International Strategy for Disaster Reduction) (2004) Living with Risk - A Global Review of Disaster Reduction initiatives. UN/ISDR, Geneva.

\section{WHAT DO YOU THINK?}

To discuss this paper, please email up to 500 words to the editor at journals@ice.org.uk. Your contribution will be forwarded to the author(s) for a reply and, if considered appropriate by the editorial panel, will be published as a discussion in a future issue of the journal.

Proceedings journals rely entirely on contributions sent in by civil engineering professionals, academics and students. Papers should be 2000-5000 words long (briefing papers should be 1000-2000 words long), with adequate illustrations and references. You can submit your paper online via www.icevirtuallibrary.com/content/journals, where you will also find detailed author guidelines. 